A system of parallel wires was attached to the grid and plate terminals of the valve. For every position of a movable condenser joining the wires there was a definite pair of values for the grid potential $V_{g}$ and the emission current $i_{e}$ which set up oscillations of maximum strength. From $V_{g}$ and $i_{e}$, and from the construction data of the valve, it is possible to cal. culate the total number $N$ of the electrons between grid and plate. ${ }^{3}$ In Fig. 1 the observed wave-lengths $\lambda$ are plotted against the values $1 / \sqrt{ } N$ for the following valves: Philips D II, Z I, TA 0810, Radiotechnique R 5, Zenith W $20 \mathrm{~A}$.

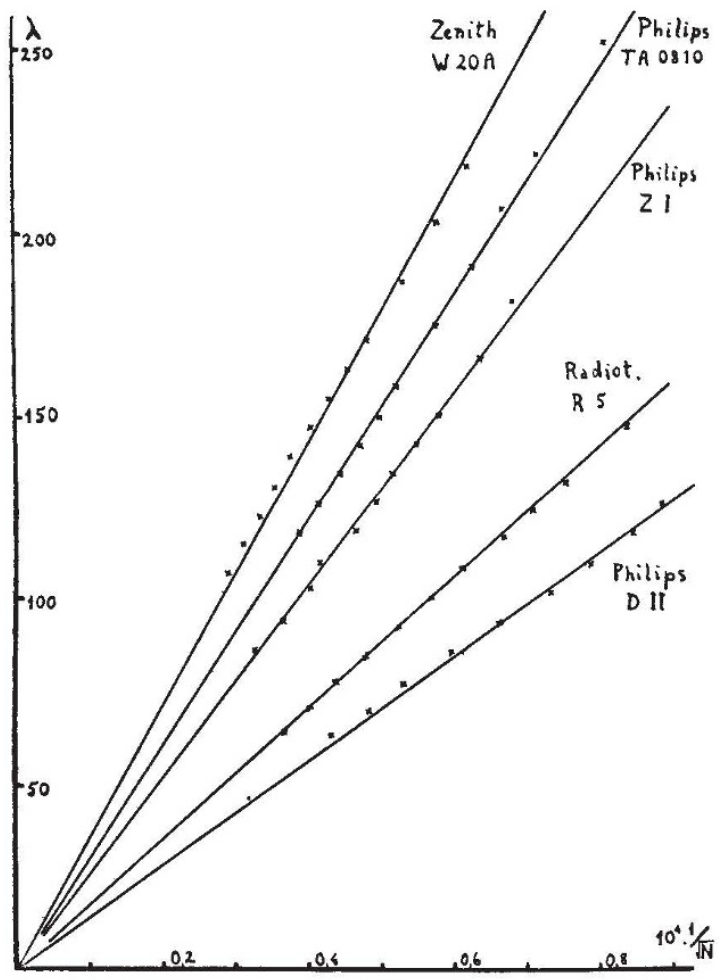

FIG. 1.

The experimental data seem to follow closely enough the theoretical relation $\lambda \sqrt{ } N=$ const $=K$. The values of the constants $K$ for different valves (representing the tangent of the straight lines in the figure) are in reasonably good agreement with the theoretical value (calculated for parallel plane electrodes, omitting space charge effects) $K=\mathbf{3} \cdot 35 \times 10 \sqrt[6]{v, v}$ being the volume comprised between grid and plate of the valves; this is shown in the following table:

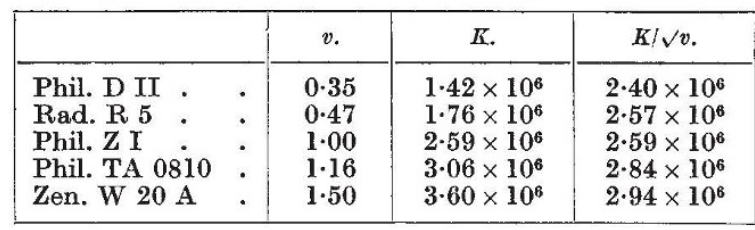

Physical Institute,

Antonio Rostagni.

University of Turin, July 31.

1 Atti R. Acc. Sc., Torino, 66, No. 1, p. 123; No. 2, p. 217; No. 3, p. 383 ; 1931. E. W. B. Gill (Phil. Mag., 13, 734; 1932) seems not to have noticed that in these papers I showed in particular how the condition for the maintenance of the oscillations $f$ eidt $<0$, is satisfied (No. 1, p. 128 ; No. 3, p. 393).

See, for example, E. W. B. Gill, Phil. Mag., 44, 161; 1922

s Atti R. Acc. Sc., Torino, 66, No. 1, p. 123; No. 3, p. 383; 1931.

\section{Science Teaching in Schools}

IN several recent issues of Nature it is suggested that the science teaching in schools is lifeless and dominated by the curse of useless external examinations. I learn that as a result there is little scientific interest or knowledge among the masses, and finally I am cast down by a fearsome picture of the horrors of the machine which science has created.

Turning for consolation to educational periodicals and my colleagues, I find the same story and an atmosphere of desolation such as one associates with a Russian novel.

Unfortunately, this is all true. I cannot say that the position has been exaggerated or put without moderation. Surely the state into which we have drifted has been outlined clearly enough to demand that it is now time to do something. Surely science teachers can get together and devise some way out of our trouble, despite the handicap which our specialised university training has given us. Government regulations make it a condition of State aid that a school shall provide facilities for the teaching $o$. science. State - recognised examinations, towards which that teaching is supposed to lead and by which it is valued, permit of a pass on 'Heat, Light, and Sound'

It is useless to blame the examiner or the teacher. It is the system which accepts such outward and visible signs in place of inward grace which must be fought. Would it not be possible for those of us who have not died mentally under the strain, to band together with the sole aim of improving the outlook ? We can leave the economics of the profession to the professional associations. We can sink differences of opinion and teaching rank, and whether elementary school or university teachers, pledge ourselves to claim, in season and out, our right to teach science and not just ' Heat, Light, and Sound'.

The pages of NATURE have been used with moderation and wisdom in outlining this problem. May we look to NATURE to give a lead to such a crusade? It is not the task of many individuals, but of a united body, the members of which are fired with that spirit of untiring pursuit which has marked so much of the history of science.

The King's School,

W. F. F. SHEARCrofrt.

Peterborough.

\section{The Sense of Smell of .Cats}

I HAD a favourite cat which was having fits and becoming dangerous, so, to destroy it as painlessly as possible, I inserted several grains of morphia in the centre of a piece of foie gras which was cut in two, great care being taken that no morphia was spilt on the outside. The cat on being shown the foie gras expressed in every way its eagerness for it, but when it got within three feet of the foie gras, turned round and looked at me with intense astonishment, and then after another sniff walked away, though previously it had always worried for a small piece. The special point is that the eat could detect something dangerous through the strong smell of the foie gras, though morphia, even in considerable quantities, has to most persons only a faint odour.

\section{F. W. Edridge-GreEn.}

99 Walm Lane, Willesden Green, London, N.W.2, Sept. 13 